\title{
Breaking The Traditional Communication Flow: Exploration of Social Media Opinion Leaders in Health
}

\author{
Emma Mohamad ${ }^{1, *}$, Abdul Latiff Ahmad ${ }^{1}$, Sabariah Mohamed Salleh ${ }^{1}$ and Ummu \\ Khadijah Wan Sulaiman ${ }^{1}$ \\ ${ }^{1}$ School of Media and Communication, Faculty of Social Sciences and Humanities, Universiti \\ Kebangsaan Malaysia, 43600 UKM Bangi Malaysia
}

\begin{abstract}
Opinion leaders play an important role in mitigating health issues and are able to influence attitudes and health behaviors to a certain extent. However, in the world we are living today, individual health decision making no longer rely fully on doctor's advice, but often persuaded by people or organisations deemed reliable and trustworthy. Interestingly, one does not have to have a medical degree to be seen as "reliable" or "trustworthy" in giving out medical advices. Computermediated-communication changes the way opinion leaders emerge in virtual communities, specifically in the context of health. Through increased access to both traditional and online media, people have a fair access to communication technology and therefore, our definition of opinion leaders have shifted from how we used to understand it through Lazarsfeld's two-steps flow theory. In fact, the way opinion leaders operate via social media platform is very different from how it used to be through the traditional mass media. This paper will discuss on the characteristics of new media opinion leaders, particularly in the context of health, in hopes to learn new ways to promote health in future communication campaigns.
\end{abstract}

\section{Introduction}

Communications via the new media platform plays an important role in different aspects of our day-to-day life. Different patterns of interactions on the web and on social media challenged traditional theories of understanding how the circuit of mass communication works. Computer-mediated-communication changes the way opinion leaders emerge in the virtual community and how they operate is different from how we used to understand it through Lazarsfeld's two-steps flow theory.

Lazarsfeld et. al. [1] argued that opinion leaders are the first ones exposed to (traditional) media content, forms opinions on the issues that was discussed and infuse their opinions to the public. This infiltrated opinion will then later shape public opinion. In the present scenario however, this model is rendered problematic. In this day and age, we have

* Corresponding author: emmamohamad@ukm.edu.my 
increased access to both traditional and online media, and even though digital divide is still present, people have a fair access to communication technology. Therefore, our definition of opinion leaders have shifted and is no longer limited to those who have access to the media. In fact, the way opinion leaders operate via social media platform is very different from how it used to be through the traditional mass media. This paper intend to explore how the definition and conceptualization of opinion leaders facilitated by communication technology have evolved particularly in health.

\section{Changes in the way opinion leaders operate : Rethinking Two Steps Flow theory}

First introduced almost seven decades ago, the Two Steps Flow Theory has served as a significant model in communication and is extensively utilised in many studies. Lazarsfeld et al [1] found that opinion leaders have certain influence towards the society through interpersonal communication. It is suggested that the more frequent and effective personal contact between opinion leaders and society, the more they can influence people's perception, motivation, attitude and actions.

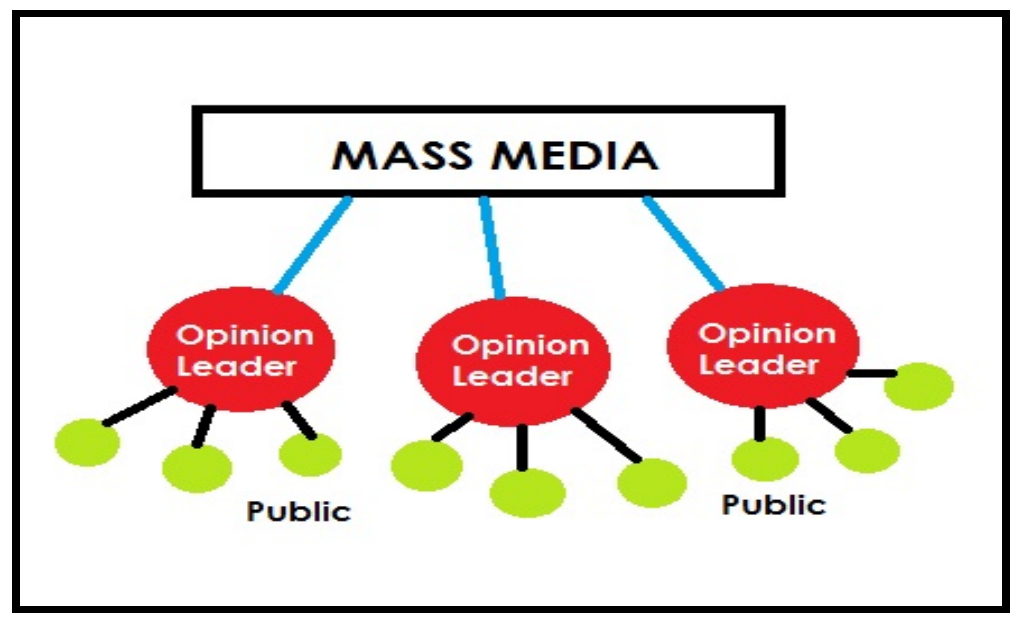

Fig. 1. Lazarsfeld et. al. Two-steps flow theory

However, the two steps flow theory only discussed how opinion leaders influence society through interpersonal communication, which is not entirely suitable anymore in our current environment today. This is mainly because mass media content is now accessible directly to society, thus opinion leaders might not able to control public opinion entirely.

Media scholars continue to debate on the relevance of opinion leaders in communication processes as well as the flow of communication itself. The idea of having 'multi steps', rather than just 'two steps' in communication flow from mass media to the public began to evolve and was accepted as the new way of looking at information dissemination. The multi steps flow suggests that communication can be multi directional and not limited to a one way street connected by opinion leaders. In fact, information flow can reverse from the public to the mass media through audience feedback process. Not only the multi steps flow better explains communication processes in current media landscape, it also acknowledges audiences as active media users. The process of forming public opinions also becomes more complex to understand but also very dynamic, whereby different groups of publics can influence other sets of publics when they share insights with each other. 


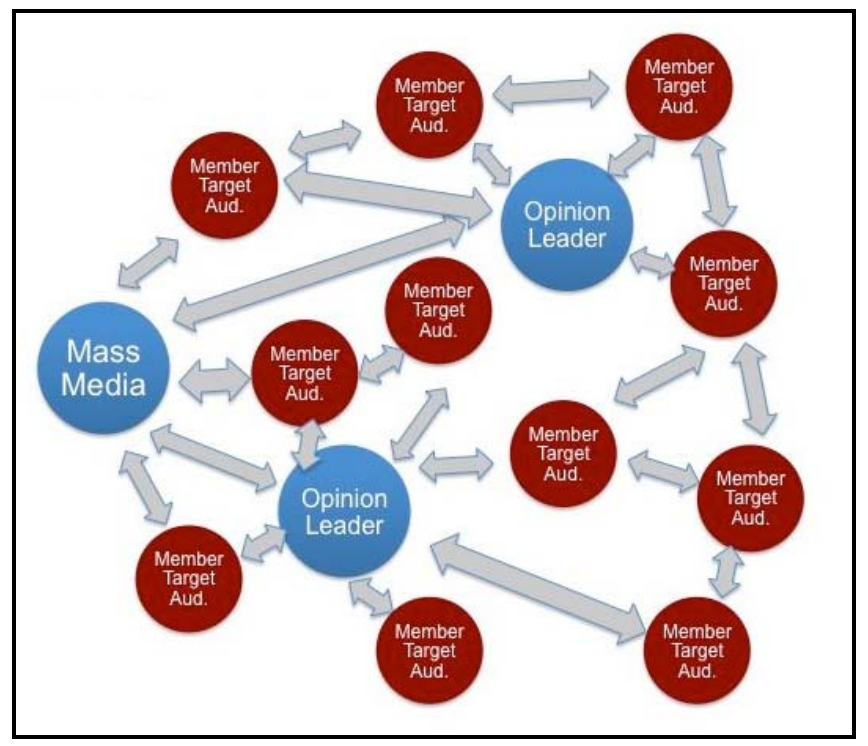

Fig. 2. Multi-steps flow.

The multi steps flow model also suggests that mass media messages can differ considerably from the original message. This is due to the exchange of meanings and interpretations by individuals who will then alter the original message according to his or her own understanding, hence giving it a new meaning. This new meaning will then be passed on and shared to other individuals, who then may also add on another layer to recontextualise the message.

Yet opinion leaders remained significant, but shifted its role and influence in a different direction. Secondly, the development of contemporary media creates a new breed of opinion leaders. These parasocial opinion leaders are more reachable virtually and easier to interact with rather than the traditional opinion leaders. The way they work to influence society's perception, motivation, attitude and actions through social media is also different than the traditional way. The multi steps flow is also known as diffusion of innovation theory developed by Everett Rogers in the 1960s. This theory specifically studies how innovation envelops through four stages i.e : invention, diffusion, time and consequences, whereby opinion leaders are seen as playing an important role in facilitating people's acceptance of new innovation.

With the increase of public's access to mass media content, one could argue that opinion leaders may lose its pressence and importance. After all, any individuals can form their own opinions based on how they understand media messages, and do not rely on opinion leaders to help them form judgement towards an issue. However, on the contrary, new media opinion leaders are stronger in pressence and increased persuasiveness in forming public opinion. Social media phenomenon in particular have witnessed the rise of opinion leaders in many areas, for example politics, fashion and health. Therefore it is important that researchers re-examines the structure and communication processes around digital/virtual opinion leaders to better understand why opinion leaders remain strong (if not stronger) in influencing public's opinion even when society nowadays are considered as active audience and media users. 


\section{Health opinion leaders : Local and international examples}

In health communication, opinion leaders play an important role in persuading heath actions. A systematic review published in Cochrane by Flodgren et al. [2] found that opinion leaders alone or in combination with other interventions may successfully promote evidence-based practice. However the review found that in most studies, the role of opinion leader was not thoroughly examined and it is therefore unclear as to what is the best method to optimize the effectiveness of opinion leaders, and whether social media can play a role in influencing behaviours. It is timely that we re-examine the traditional way of defining opinion leaders and relook at its strategy in health communication.

Opinion leaders play a role in mitigating health issues and able to influence attitudes and health behavior to a certain extent. However, in this $21^{\text {st }}$ century, individual health decision making no longer rely fully on doctor's advice, but often persuaded by people or organisations deemed reliable and trustworthy. Interestingly, one does not have to have a medical degree to be regarded as "reliable" or "trustworthy". In fact, thanks to the Internet, health opinion leaders may even transpire from small and marginalized group or people.

This paper will generally explore 5 Malaysian instagram accounts (considered opinion leaders in health). Investigation on these instagram content serves as an early exploration to find out what these health opinion leaders have in common. This preliminary observation on characteristics health opinion leaders have may help guide / give directions to further research on social media opinion leaders, particularly in relations to the communication flow and process.

Selection of these instagram users are random, based on several categories i.e: lifestyle, exercise, diet, sports and illness/health issue. We observed five latest instagram posts related to health posted by these five selected users. The five chosen opinion leaders are as listed in Table 1 below:

Table. 1. Instagram Opinion Leaders in Health.

\begin{tabular}{|c|c|c|c|c|}
\hline Numb. & Instagram opinion leader & Instagram name & Category & $\begin{array}{c}\text { Number of } \\
\text { Followers }\end{array}$ \\
\hline 1. & $\begin{array}{c}\text { Khairy Jamaluddin (Minister } \\
\text { of Youth and Sports) }\end{array}$ & Khairykj & Sports & $390 \mathrm{~K}$ \\
\hline 2. & Kevin Zahri & Kevinzahri & $\begin{array}{c}\text { Fitness and } \\
\text { Weight Loss }\end{array}$ & $155 \mathrm{~K}$ \\
\hline 3. & Meameao & Meameao & Healthy Diet & 9189 \\
\hline 4. & Nana Al- Haleq & Nanaalhaleq & Fitness & $14.1 \mathrm{~K}$ \\
\hline 5. & Sharifah Sakinah & Sharifah_Sakinah & Exercise & $966 \mathrm{~K}$ \\
\hline
\end{tabular}

Generally all these five opinion leaders have several characteristics in common through observations of their health-related postings. Firstly, they walk the talk. All of them do not just preach about the importance of health, they become the example of what they believe in. For example, Khairy Jamaluddin is not just popular because of his status as Malaysia's Minister of Youth and Sports, he also shows that he is involved and trying to push himself to try new sports/activities. His latest post for example showed him crossing the finish line for Ironman 70.3 in Putrajaya. In his caption, he emphasised on the importance of having a positive mind and to be successful. He also shared how hard it was for him to complete the challenge and that showed his vulnerable side, something that could appeal to a lot of people.

Secondly, all these opinion leaders publish instagram posts that are aimed to inspire people to become like them. This inspiration and aspiration content can be seen in their achievements, for example through their weight loss and toned bodies, Sharifah Sakinah is an example who puts up pictures showing off her lean muscles, and are often pictured in 
the gym, working out. She is also an example who lost weight considerably and her 'before and after' pictures are a type of inspiration to others.

Thirdly, all these opinion leaders breathe and live health. They are not pretentious in their postings, often seen wanting others to achieve what they have achieved and willing to share their 'secret' to success. Meameao for example, do not only posts delicious looking healthy cuisines, she shares all her recipes in her instagram captions. This shows that she cares about her followers and that help to build a community of followers and build social support. Social media allows for great growth in online community and this is apparent in these opinion leaders' instagram account.

These three characters observed are seen consistent across all the five opinion leaders instagram pictures. While these characters are not exhaustive, they provide some ideas on how changes can occur in communication flow of social media opinion leaders in health. Therefore more indepth research should be carried out to better understand the changes in new media opinion leaders.

\section{The way forward for health campaigners}

Katz [3] highlights the debates on whether opinion leadership is formed by generalised trait or by issues (which then produces specialised opinion leaders). Indeed as Merton [4] had emphasized very much earlier on that opinion leaders on "local" issues are different than the "cosmopolitan" opinion leaders. After analysing examples in both local and international context, this paper would like to suggest that key players in healthcare to consider "specialised" opinion leaders through promoting or campaigning on health.

Social media platform in particular provides a big opportunity for health practitioners and health promoters to tap into via opinion leaders and social media celebrities. It is high time that we move from relying fully on the traditional forms of campaigning on health, by utilizing ready-made resources, or by grooming new online opinion leaders. By way of understanding both the new conceptualization and communication processes of these opinion leaders, health messages can be disseminated in a more effective manner, despite maintaining its nature of mass communication. Persuasion via online opinion leaders is impactful because of the specific-ness of health issue discussed, but also more importantly is the persona of these opinion leaders, leaving feelings of inspiration and aspiration to its audience/followers.

\section{References}

1. P. F. Lazarsfeld, B. Berelson, H. Gaudet. The People's Choice. (1944)

2. G. Flodgren, E. Parmelli, G. Doumit, M. Gattellari, M.A. O'Brien, J. Grimshaw, \& M.P. Eccles. Cochrane Database of Systematic Reviews, 8. (2011).

3. E. Katz, Int. J. Comm., 9, 1023-1028. [http://repository.upenn.edu/cgi/viewcontent.cgi?article=1407\&context=asc_papers]

4. R.K. Merton. Communications research (1949) 